\title{
Correction to: Human Trafficking Prevention Efforts for Kids (NEST)
}

\author{
Yvonne G. Williams
}

\section{Correction to:}

Chapter 17 in: L. Walker et al. (eds.), Handbook of Sex

Trafficking, https://doi.org/10.1007/978-3-319-73621-1_17

This chapter has been updated to remove identifying information. 